\title{
Screen-based sedentary behavior and associations with functional strength in 6-15 year-old children in the United States
}

\author{
Lisa R. Edelson ${ }^{1 *}$, Kevin C. Mathias', Victor L. Fulgoni III ${ }^{2}$ and Leonidas G. Karagounis ${ }^{1}$
}

\begin{abstract}
Background: Physical strength is associated with improved health outcomes in children. Heavier children tend to have lower functional strength and mobility. Physical activity can increase children's strength, but it is unknown how different types of electronic media use impact physical strength.

Methods: Data from the NHANES National Youth Fitness Survey (NNYFS) from children ages 6-15 were analyzed in this study. Regression models were conducted to determine if screen-based sedentary behaviors (television viewing time, computer/video game time) were associated with strength measures (grip, leg extensions, modified pull-ups, plank) while controlling for potential confounders including child age, sex, BMI z-score, and days per week with 60+ minutes of physical activity. Grip strength and leg extensions divided by body weight were analyzed to provide measures of relative strength together with pull-ups and plank, which require lifting the body.

Results: The results from the regression models showed the hypothesized inverse association between TV time and all strength measures. Computer time was only significantly inversely associated with the ability to do one or more pull-ups.

Conclusions: This study shows that television viewing, but not computer/videogames, is inversely associated with measures of child strength while controlling for child characteristics and physical activity. These findings suggest that "screen time" may not be a unified construct with respect to strength outcomes and that further exploration of the potential benefits of reducing television time on children's strength and related mobility is needed.
\end{abstract}

Keywords: Children, Sedentary behavior, Screen time, Strength, Television, NHANES

\section{Background}

Children's physical strength and cardiorespiratory fitness are related to a variety of health outcomes such as risk of cardiovascular, musculoskeletal, and metabolic conditions, as well as improvements in general mobility and physical functioning [1-4]. The importance of maintaining adequate levels of physical activity throughout life is widely recognized [5]. Given the plethora of research on the benefits of physical activity, current physical activity guidelines for children ( $>6$ years of age) and adolescents in the US recommend at least 60 minutes per day of moderate- to vigorous-intensity physical activity (MVPA) and at least 3 times a week of weight bearing

\footnotetext{
* Correspondence: Lisarobin.edelson@rdls.nestle.com

${ }^{1}$ Nestlé Research Center, Case Postale 44, CH-1000 Lausanne, Switzerland Full list of author information is available at the end of the article
}

exercises to promote muscle and bone strength (Physical Activity Guidelines for Americans, U.S. Dept. of Health and Human Services). Similar recommendations are in place globally [6].

Inactivity is widely accepted to be related to increased BMI [7, 8], but the relationship between BMI and strength, at first glance, seems to be mixed. A study by Ervin and colleagues [9] found that obese and overweight children in the United States had greater gripand leg strength, but lower core and upper-body strength than normal weight children. This difference in findings between the two sets of strength measures likely lies in the fact that the core and upper-body strength measures used (plank and a modified pull-up, respectively) both involve lifting the child's own body, whereas the grip strength and leg extensions used absolute 
measures of strength (number of pounds of force squeezed or pushed). This distinction between absolute strength (e.g., how much weight an individual can lift at the gym) and relative or functional strength (what that person can do with their own body) is an important one, with the latter being likely more relevant to the individual's mobility and quality of life. As overweight and obese children often present with compromised locomotor function compared to non-obese children [10], it is important to consider their strength in relation to their body size. It is for this reason that assessments in clinical settings generally adjust for the patient's weight status when judging their ability to perform daily tasks [e.g., [11]]. In the current study, we focused on children's relative strength by dividing all measures of absolute strength (e.g., amount of force in leg extensions) by the child's weight $(\mathrm{kg})$ to get a sense of how the strength could be used functionally by the child (e.g., to walk up stairs).

Although the role of physical activity in building strength is well documented, less is known about the relationship between sedentary behaviors such as screen time (watching television, playing video games) and children's strength. In the past, it has been hypothesized that sedentary behavior may simply reflect a lack of physical activity, but studies have shown that these two behaviors are not mutually exclusive $[12,13]$. This is particularly problematic in studies which use measures of sedentary behavior, such as television viewing time, simply as a proxy for physical activity levels $[14,15]$. In the current study, we specifically explore the relationship between the amount of time spent in different screen-based sedentary behaviors and strength while controlling for reported physical activity.

The objective of the present study was to utilize the available data from the 2012 National Health and Nutrition Examination Survey (NHANES) National Youth Fitness Survey (NNYFS) to explore the relationship between different screen time activities and strength in a nationally representative sample of US youth. To this end, we report on the relationship between strength of core-, lower- and upper body muscles and screen time in children between 6-15 years of age in the US.

\section{Methods}

The National Health and Nutrition Examination Survey (NHANES) is a series of nationally representative surveys of the health and nutritional status of adults and children in the United States, comprising both questionnaire and physical examination components. The NHANES National Youth Fitness Survey (NNYFS) was conducted in 2012 as a supplement to the main NHANES survey. It was designed to collect data on physical activity and fitness in American children ages 3 to 15 years [16]. Fitness tests were administered to learn more about the physical health of the children in this age group.

\section{Participants}

The sampling for the 2012 NNYFS [17] was conducted in conjunction with NHANES. Both samples were selected using a multistage, stratified area probability samples of non-institutionalized individuals and were weighted to provide nationally representative estimates for the United States population. Of the households selected to participate in the NNYFS, $98.5 \%$ responded to the screening invitation. The interview response rate was $79.4 \%$ and the examination response rate was $96.1 \%$ (conditional on completing the interview). Additional details on the study design and measures have been published by Johnson and colleagues [16]. Not all of the strength measures were conducted with children less than 6 years of age, therefore the current analyses were restricted to children aged 6-15 years. The final sample included 1224 children.

\section{Procedures}

Demographic, socioeconomic, physical activity, and electronic media use (e.g., television viewing) were recorded during a household interview [17]. Information from 611 year-old children was obtained from proxy respondents and 12-15 year-old children answered the physical activity and media use questions themselves. Anthropometric measurements (height and weight) and strength measures were obtained by trained examiners in a mobile examination center [18].

\section{Physical activity}

One questionnaire item assessed physical activity. Physical activity was reported as the number of days in the past week that a child spent a total of at least 60 minutes participating in any physical activity that increased heart rate or resulted in breathing hard some of the time [19]. The response values ranged from 0 to 7 days.

\section{Electronic media use}

Two separate questions provided information about children's electronic media use. Television time was reported as the average number of hours per day over the past 30 days that a child spent watching television or videos. Computer usage was reported as the average number of hours per day over the past 30 days that a child used a computer or played video games outside of work- or school-related activities, not including time previously mentioned in the TV item (if children watched videos on the computer) [19]. For each question, participants could respond that they did not do this activity (0 hours), or that they did it on average for less 
than an hour, 1 hour, 2 hours, 3 hours, 4 hours, or 5 or more hours per day.

\section{Strength}

Four different measures of physical strength were measured in the mobile examination center: grip strength, leg extension strength, number of modified pull-ups and plank time. Grip strength assessed upper-body muscle strength using a hand-grip dynamometer (Takei Digital Grip Strength Dynamometer, Takei Scientific Instruments Co., Ltd). Participants were instructed to squeeze the handle of the dynamometer as hard as possible three times with each hand [20]. The strongest of the six measurements was included in the analysis. Leg extension strength assessed lower-body strength using a beltstabilized hand-held dynamometer (HHD, MicroFET2, Hoggan Health Industries). Participants sat in a chair and were restrained at the hips, thighs and trunk with web belts. The dynamometer was placed perpendicular to the shin near the ankle bones and the participants were instructed to press their leg forward as hard as possible into the dynamometer [21]. Three measurements were taken for each leg and the strongest of the six measurements was included in the analysis. The plank test (a horizontal body position held with only the hands/ forearms and toes touching the floor) assessed core muscle strength and endurance. Participants started lying face down on a mat and then the duration (in seconds) that they could hold the plank position was measured [22]. The modified pull-up assessed upper-body strength. Participants lay on their backs and used their arms to pull themselves up to a strap hanging down 8 inches from the center of the bar [23]. The number of completed pull-ups was included in the analysis. It should be noted that both the grip and leg strength tests assessed absolute muscle strength, whereas the modified pull-up and plank tests involve lifting the weight of the body and therefore are relative measures of strength/endurance in proportion to body weight. In addition to analyzing absolute grip and leg strength, these measures were also converted into relative strength measures with respect to body weight by dividing the absolute grip and leg strength recorded by the weight of the child $(\mathrm{kg})$.

\section{Data analysis}

For the descriptive analyses of physical activity, TV and computer time, and absolute- and relative strength measures, children's data are presented divided into three age groups that roughly represent elementary-school age (6-9), pre-adolescence (10-12), and early adolescence (13-15). Initially, simple linear regression models were used to examine trends across these variables. Due to the potential of rounding and the discrete nature of $\mathrm{TV}$ and computer time, a non-parametric test extending the
Wilcoxon rank-sum test was conducted to test for trends across the ordered age groups to confirm the robustness of the findings from the simple linear regression models.

Additionally, a series of multiple linear regression models controlling for age, sex, physical activity, and BMI $z$-score were utilized to determine the associations of television time and computer time with absolute- and relative strength measures. The number of hours of both television time and computer time were modeled as continuous variables. Children reporting " $<1$ hour" were assigned the midpoint of 0.5 hours given that it was also possible to report 0 or 1 hour. The questionnaire limited the maximum number of hours children were able to report to a maximum of " 5 hours or more" of TV or computer time per day. Children in this category were assigned a value of 5 hours in the regression models.

Due to the high percentage of children who were unable to complete one modified-pull, the appropriateness of an ordinary least-squares regression model was questionable for that portion of the analysis. For the adjusted analysis of modified pull-ups, both a logistic ( 0 versus $\geq 1$ modified pull-up) and a linear regression model conditional on the child being able to complete at least 1 modified pull-up were conducted to address the analytical issue of high percentages of zeroes in the data. The logistic regression model estimated the change in the odds that a child could complete at least one modified pull-up and the regression model estimated the change in number of modified pullups completed, using only children that could complete at least one modified pull-up. For all models, both television and computer time were included simultaneously to examine if there were separate pathways by which television and computer time were associated with strength.

The statistical tests for trends across the three age categories were conducted using STATA 13.1 (StataCorp, College Station, TX). All other analyses were conducted using SAS 9.3 (SAS Institute Inc.; Cary, NC) and SUDAAN 11 (Research Triangle Institute, Research Triangle Park, NC, USA). With the exception of the sensitivity analysis utilizing an extension of the Wilcoxon rank-sum non-parametric test (nptrend command, STATA 13.1), all analyses accounted for the complex survey design of the NHANES datasets. Analytical weights based on probabilities of selection and participation in the study were utilized, resulting in estimates representative of the US population. Primary sampling units (geographical area) and strata from the first stage of the sampling design were accounted for in estimation of the standard errors. A criterion of $(p<0.05)$ was used for all tests of statistical significance.

\section{Ethics, consent, and permissions}

The National Center for Health Statistics (NCHS) Research Ethics Review Board approved all NHANES protocols. A parent or legal guardian of each participant 
provided informed consent and participants who were at least 7 years old also provided written assent before any questionnaires or measurements were administered.

\section{Results}

Characteristics of the analytical sample are provided in Table 1. Of the original 1224 participants, 26 subjects were missing data for grip strength, 34 were missing leg strength, 29 were missing modified pull-up data, and 21 were missing plank data.

\section{Changes in activity and strength with age}

Distributions of physical activity for all three age categories are reported in Table 1. A significant trend

Table 1 Sample characteristics and days per week of physical activity among the 2012 NHANES National Youth Fitness Survey participants

\begin{tabular}{|c|c|c|c|c|}
\hline & $\begin{array}{l}6-9 \text { y } \\
n=491\end{array}$ & $\begin{array}{l}10-12 y \\
n=379\end{array}$ & $\begin{array}{l}13-15 y \\
n=354\end{array}$ & $\begin{array}{l}\text { Full sample }(6-15 \text { y) } \\
n=1224\end{array}$ \\
\hline $\begin{array}{l}\text { Subject } \\
\text { Charateristics }\end{array}$ & $\begin{array}{l}\% \text { of } \\
\text { sample }^{\text {b }}\end{array}$ & $\begin{array}{l}\text { \% of } \\
\text { sample }^{b}\end{array}$ & $\begin{array}{l}\% \text { of } \\
\text { sample }\end{array}$ & $\begin{array}{l}\% \text { of } \\
\text { sample }^{\text {b }}\end{array}$ \\
\hline \multicolumn{5}{|l|}{ Sex } \\
\hline Female & 47 & 50 & 50 & 49 \\
\hline \multicolumn{5}{|l|}{ Race/Ethnicity } \\
\hline $\begin{array}{l}\text { non-Hispanic } \\
\text { White }\end{array}$ & 52 & 54 & 55 & 54 \\
\hline $\begin{array}{l}\text { non-Hispanic } \\
\text { Black }\end{array}$ & 14 & 12 & 15 & 14 \\
\hline Hispanic & 22 & 24 & 22 & 23 \\
\hline Other & 11 & 10 & 8 & 10 \\
\hline \multicolumn{5}{|l|}{ Weight Status ${ }^{c}$} \\
\hline Underweight & 3 & 4 & 3 & 3 \\
\hline Normal Weight & 65 & 53 & 61 & 60 \\
\hline Overweight & 14 & 25 & 17 & 18 \\
\hline Obese & 19 & 19 & 20 & 19 \\
\hline \multicolumn{5}{|l|}{$\begin{array}{l}\text { Days of Physical } \\
\text { Activity per Week }\end{array}$} \\
\hline 0 days & 2 & 5 & 7 & 4 \\
\hline 1-3 days & 10 & 19 & 29 & 18 \\
\hline 4-6 days & 26 & 32 & 40 & 32 \\
\hline 7 days & 62 & 43 & 24 & 46 \\
\hline $\begin{array}{l}\text { Mean }(95 \% \text { Cl) } \\
\text { (Days) }^{d}\end{array}$ & $\begin{array}{l}5.9(5.7- \\
6.1)^{* * *}\end{array}$ & $\begin{array}{l}5.1(4.8 \\
-5.3)\end{array}$ & $\begin{array}{l}4.4(4.2 \\
-4.6)\end{array}$ & $5.2(5.0-5.4)$ \\
\hline
\end{tabular}

aphysical activity was self- or proxy reported as the number of days that the child was physically active (increased heart rate or breathing hard some of the time) for a total of at least 60 minutes in the past 7 days)

${ }^{b}$ Nationally representative estimates taking into account the survey design of the 2012 NNYFS

${ }^{c}$ Weight status of children were based on BMI-for-age percentiles

${ }^{d} A$ linear trend across the three age categories for average days of physical activity was tested using a simple linear regression model accounting for the survey design of the 2012 NNYFS

***Indicates a significant regression coefficient for a linear trend $(p<0.001)$

across the three sub age groups across age categories $(p<0.001)$ was shown with decreasing days spent exercising among older children. Distributions of time spent watching TV or using the computer are reported in Table 2. The results show older children spent more time watching TV and using computers/video games outside of school than did younger children (trend across age categories for TV: $p<0.001$ and computer: $p<0.001$ ). Distributions of absolute and relative strength measures are presented in Table 3. Significant increases in absolute and relative measures of children's strength were shown with increasing age; however, older children were less likely to be able to complete at least one modified pull-up ( $p=0.029)$.

\section{Electronic media use and associations with strength}

The results from the regression models showed the hypothesized inverse association between TV time and all strength measures (Table 4). The associations between computer time and strength measures only reached significance for the odds of completing one or more pullups.

\section{Discussion}

It has been previously reported that children in higher BMI categories have greater absolute measures of grip strength and leg extension power, but have lower core and upper body strength when compared to children with lower BMI [9]. However, despite greater absolute leg strength, overweight and obese children show more limited mobility compared to non-obese children [10]. For this reason, it is important to consider an individual's strength relative to their size to better understand the efficiency with which they can move their body (e.g., walk up stairs, jump) as these are measures that can influence a child's current and future quality of life, whereas the child's absolute strength (e.g., lifting weights) may be a less meaningful measure of his/her physical functioning. To this end, in the current study, we reported the effect of different types of electronic media use on measures of both absolute- and relative strength in children.

The amount of time spent viewing television was significantly inversely associated with both absolute and relative strength measures, even when controlling for potentially confounding variables such as age, sex, BMI, and physical activity. These findings are consistent with previous studies that showed inverse associations between sedentary behavior and physical fitness (e.g., running a mile) or flexibility [24-26]. However, in contrast to the current findings, the one previous study (published in 1998) that explored children's strength as an outcome found no association between television viewing and strength [25]. The differences between the two studies could be due to changes in patterns of sedentary 
Table 2 Number of hours per day children reported watching TV watching or playing computer/ video games

\begin{tabular}{|c|c|c|c|c|c|c|c|c|}
\hline & 0 Hours & $<1$ Hour & 1 Hour & 2 Hours & 3 Hours & 4 Hours & $5+$ Hours & Mean $(95 \% \mathrm{Cl})^{\mathrm{a}}$ (Minutes) \\
\hline TV Time $^{b}$ & \multicolumn{8}{|c|}{$\%$ of Sample } \\
\hline $6-9 y$ & 1 & 17 & 30 & 32 & 12 & 4 & 3 & $103(91-115)^{* * *}$ \\
\hline $10-12 y$ & 1 & 14 & 21 & 34 & 15 & 6 & 8 & $125(111-138)$ \\
\hline $13-15 y$ & 2 & 12 & 21 & 29 & 21 & 9 & 8 & $130(121-139)$ \\
\hline Full sample (6-15 y) & 1 & 15 & 25 & 32 & 16 & 6 & 6 & $117(109-126)$ \\
\hline \multicolumn{9}{|l|}{ Computer Time ${ }^{c}$} \\
\hline $6-9 y$ & 12 & 41 & 26 & 12 & 5 & 2 & 2 & $61(54-67)^{* * *}$ \\
\hline $10-12 y$ & 12 & 31 & 24 & 17 & 10 & 3 & 3 & $78(67-88)$ \\
\hline $13-15 y$ & 10 & 23 & 16 & 20 & 14 & 10 & 8 & $114(99-125)$ \\
\hline Full sample (6-15 y) & 11 & 33 & 23 & 16 & 9 & 5 & 4 & $80(73-88)$ \\
\hline
\end{tabular}

a Linear trends across the three age categories for hours of TV or computer time were tested using simple linear regression models accounting for the survey design of the 2012 NNYFS. Due to the potential of rounding and discrete nature of these variables, a non-parametric test extending the Wilcoxon rank-sum test was conducted using STATA (version 13.1, 2013, StataCorp, College Station, TX) to test for trends across the ordered age groups to confirm the robustness of the findings from the linear regression models

${ }^{\mathrm{b}}$ Television time estimated based on self-report of the average hours per day over the last 30 days

${ }^{c}$ Computer or video game time outside of work or school estimated based on self-report of the average hours per day over the last 30 days

***Indicates a significant linear trend $(p<0.001)$ across age groups for both the linear regression model (regression coefficient) and the extension of the Wilcoxonrank sum (non-parametric) test

habits and availability of screen-based media in children's homes in the last 20 years [27-29].

It should be noted that the partial $r^{2}$ values (data not shown) showed that although television viewing time was significantly associated with child strength, this variable explains a relatively small portion of the variance in strength $(\sim 1 \%)$, compared to other variables, such as BMI z-score (partial $r^{2}$ between 6-36 \%) or child age (1$12 \%)$. Unlike some of the child characteristics such as age or sex that cannot be changed, television viewing is a behavior that can be modified and would likely have health benefits beyond improving child strength. While television viewing alone explains a small portion of the variance in relative strength directly, it may have a larger impact on relative strength through changes in BMI. Previous intervention studies in children have shown that reducing television viewing can decrease BMI [30, 31], and a lower BMI z-score was associated with higher relative strength in the current study. These findings suggest that less television viewing, through reducing BMI, could result in a larger impact on relative strength, although this has yet to be explored experimentally.

In contrast with television viewing, which was inversely associated with several strength measures, time spent using the computer for leisure activities or playing video games was only associated with a child's ability to complete at least one pull-up. These findings suggest that not all sedentary behaviors, or even all types of electronic media use, are equal with respect to strength outcomes, as evidenced by the stronger inverse association between TV watching and strength measures than that between computer/video games and strength. We propose that the term "screen time" should not be considered a unified construct in the literature or in intervention studies. In fact, different types of sedentary behaviors have been associated with different risks of overweight in large-scale surveys in the United States and the Netherlands [32, 33] (but not Portuguese children [34]), as well as with different levels of energy intake in experimental studies [35]. As most of the literature on sedentary behavior or "screen time" to date has focused on time spent viewing television [36, 37], it is important to consider that other types of sedentary behavior (e.g., computer time, reading) may not have the same impacts on health and should be considered separately.

Some potential explanations for why television viewing resulted in different associations with strength compared to computer-based screen time include differences in posture or tension between passive television viewing and more engaging activities. For instance, children playing computer or video games may move more or get up more frequently. It has been reported previously in young adults that playing Ms. PacMan resulted in physiological responses and energy expenditure similar to those observed during mild-intensity exercise [38], and similar responses have also been reported for children [39]. However, it should be noted that such changes are not strong enough to replace traditional physical activity for children [39]. In contrast to the physiological response reported for computer game participation, it has previously been shown that the resting metabolic rate is lower during TV viewing compared to rest, particularly in obese children [40]. More research is needed to better understand children's behavioral and physiological processes during these different types of electronic media use, as well as during non-screen-based sedentary behaviors such as reading or doing homework. 
Table 3 Distributions of absolute- and relative strength measures

\begin{tabular}{|c|c|c|c|c|c|c|c|c|c|}
\hline & \multicolumn{5}{|c|}{ Percentiles } & \multirow[t]{2}{*}{ Mean \pm SE } & & \multicolumn{2}{|c|}{$\begin{array}{l}\text { Linear trend for difference } \\
\text { across age groups ( } p \text {-value) }\end{array}$} \\
\hline & 10 & 25 & 50 & 75 & 90 & & & & \\
\hline \multicolumn{10}{|l|}{ Absolute Strength } \\
\hline \multicolumn{10}{|l|}{ Grip $(k g)^{b}$} \\
\hline \multicolumn{10}{|l|}{ Age Group } \\
\hline $6-9 y$ & 10 & 12 & 14 & 16 & 19 & $14.1(13.7-14.6)$ & & & \\
\hline $10-12 y$ & 16 & 19 & 22 & 26 & 31 & $23.1(22.2-23.9)$ & & $<0.001$ & \\
\hline $13-15 y$ & 24 & 27 & 31 & 37 & 44 & $32.6(31.3-33.8)$ & & & \\
\hline Full sample (6-15 y) & 11 & 14 & 20 & 28 & 36 & $22.2(21.5-22.9)$ & & & \\
\hline \multicolumn{10}{|l|}{ Leg Extensions $(\mathrm{kg})^{c}$} \\
\hline $6-9 y$ & 8 & 12 & 17 & 22 & 27 & $17.7(14.9-20.5)$ & & & \\
\hline $10-12 y$ & 12 & 22 & 30 & 36 & 44 & $29.1(25.0-33.2)$ & & $<0.001$ & \\
\hline $13-15 y$ & 18 & 29 & 41 & 49 & 59 & $40.2(33.6-46.8)$ & & & \\
\hline Full sample(6-15 y) & 11 & 16 & 24 & 37 & 48 & $27.7(23.4-32.0)$ & & & \\
\hline \multicolumn{10}{|l|}{ Relative Strength } \\
\hline \multicolumn{10}{|c|}{ Grip (kg per kg of Body Weight) ${ }^{d}$} \\
\hline $6-9 y$ & 0.37 & 0.42 & 0.48 & 0.55 & 0.61 & $0.49(0.47-0.50)$ & & & \\
\hline $10-12 y$ & 0.34 & 0.43 & 0.50 & 0.57 & 0.62 & $0.50(0.49-0.51)$ & & 0.005 & \\
\hline $13-15 y$ & 0.37 & 0.45 & 0.53 & 0.60 & 0.69 & $0.53(0.51-0.55)$ & & & \\
\hline Full sample (6-15 y) & 0.37 & 0.43 & 0.50 & 0.57 & 0.64 & $0.50(0.50-0.51)$ & & & \\
\hline \multicolumn{10}{|c|}{ Leg Extensions (kg per kg of Body Weight) ${ }^{e}$} \\
\hline $6-9 y$ & 0.31 & 0.46 & 0.63 & 0.74 & 0.87 & $0.60(0.51-0.70)$ & & & \\
\hline $10-12 y$ & 0.31 & 0.47 & 0.66 & 0.77 & 0.86 & $0.62(0.54-0.70)$ & & 0.020 & \\
\hline $13-15 y$ & 0.30 & 0.47 & 0.65 & 0.82 & 0.94 & $0.65(0.54-0.75)$ & & & \\
\hline Full sample (6-15 y) & 0.31 & 0.46 & 0.64 & 0.77 & 0.89 & $0.62(0.53-0.71)$ & & & \\
\hline \multicolumn{10}{|l|}{ Plank (Seconds) ${ }^{f}$} \\
\hline $6-9 y$ & 15 & 28 & 51 & 72 & 104 & $56.9(52.5-61.3)$ & & & \\
\hline $10-12 y$ & 19 & 38 & 64 & 92 & 127 & $69.7(64.7-74.7)$ & & $<0.001$ & \\
\hline $13-15 y$ & 29 & 55 & 79 & 121 & 149 & $88.6(80.3-96.9)$ & & & \\
\hline Full sample (6-15 y) & 18 & 37 & 63 & 91 & 128 & $69.9(66.1-73.6)$ & & & \\
\hline Pullups (Repetitions) ${ }^{9}$ & & & & & & $\% \geq 1(95 \% \mathrm{Cl})^{\mathrm{h}}$ & Mean $(95 \% \mathrm{Cl})^{\mathrm{h}}$ & & \\
\hline $6-9 y$ & 0 & 0.5 & 2.9 & 6.5 & 10.2 & $81(77-86)$ & $5.7(5.3-6.0)$ & 0.029 & $<0.001$ \\
\hline $10-12 y$ & 0 & 0.6 & 3.5 & 7.6 & 11.9 & $80(76-85)$ & $6.7(5.5-7.9)$ & & \\
\hline $13-15 y$ & 0 & 0 & 4.7 & 10.1 & 19.5 & $74(69-80)$ & $9.6(8.6-10.6)$ & & \\
\hline Full sample (6-15 y) & 0 & 0.4 & 3.4 & 8.0 & 13.0 & $79(75-82)$ & $7.0(6.5-7.6)$ & & \\
\hline
\end{tabular}

${ }^{a}$ Linear trends across the three age categories for absolute- and relative strength measures were tested using simple linear regression models accounting for the survey design of the 2012 NNYFS

${ }^{b}$ Muscle strength was measured through a grip test using a handgrip dynamometer

${ }^{c}$ A digital hand-held dynamometer was used to measure the knee extension force

${ }^{d}$ Relative grip strength was estimated as a child's grip strength divided by their body weight

e Relative leg extension strength was estimated as a child's leg strength divided by their body weight

${ }^{f}$ A horizontal body position held with only the hands/forearms and toes touching the floor

${ }^{g}$ Participants lay on their backs and used their arms to pull themselves up to a strap hanging down 8 inches from the center of the bar

${ }^{h}$ Due to the large proportion of children that could not complete a modified pull-up, the analysis was conducted using two models: a logistic regression model to test a linear trend in the odds of being able to complete $\geq 1$ modified pull-up with age, and a linear regression model to test a linear trend in the number of pull-ups with age among children that could complete 1 or more modified pull-ups 
Table 4 Associations between independent variables (TV, computer/game time, age, sex, physical activity, and BMI) and strength measures

\begin{tabular}{|c|c|c|c|c|c|c|}
\hline & $\begin{array}{l}\text { TV change in } \\
\text { strength per } \\
1 \text { hr increase }\end{array}$ & $\begin{array}{l}\text { Computer change } \\
\text { in strength per } \\
1 \text { hr increase }\end{array}$ & $\begin{array}{l}\text { Age change in } \\
\text { strength per } \\
1 \text { year increase }\end{array}$ & $\begin{array}{l}\text { Sex Males - } \\
\text { Females }\end{array}$ & $\begin{array}{l}\text { Physical Activity change in } \\
\text { strength per } 1 \text { day increase }\end{array}$ & $\begin{array}{l}\text { BMI-Z-Score change } \\
\text { in strength per } 1 \text { z- } \\
\text { score increase }\end{array}$ \\
\hline & Beta $(95 \% \mathrm{Cl})$ & Beta $(95 \% \mathrm{Cl})$ & Beta $(95 \% \mathrm{Cl})$ & Beta $(95 \% \mathrm{Cl})$ & Beta $(95 \% \mathrm{Cl})$ & Beta $(95 \% \mathrm{Cl})$ \\
\hline & & & Absolute strength & & & \\
\hline $\operatorname{Grip}^{a}(k g)$ & $-0.31^{*}(-0.56,-0.06)$ & $0.05(-0.12,0.22)$ & $2.79^{* * *}(2.69,2.89)$ & $3.16^{* * *}(2.53,3.79)$ & $0.02(-0.11,0.15)$ & $1.58^{* * *}(1.30,1.86)$ \\
\hline \multirow[t]{2}{*}{ Leg Extensions ${ }^{\mathrm{a}}(\mathrm{kg})$} & $-0.99^{* *}(-1.70,-0.28)$ & $0.35(-0.42,1.13)$ & $3.31^{* * *}(2.75,3.86)$ & $1.35^{*}(0.091,2.62)$ & $-0.14(-0.57,0.29)$ & $3.22^{* * *}(2.46,3.98)$ \\
\hline & & & Relative strength & & & \\
\hline $\operatorname{Grip}^{\mathrm{a}}$ (kg per kg of body weight) & $-0.006^{*}(-0.011,-0.001)$ & $-0.002(-0.006,0.002)$ & $0.009^{* * *}(0.007,0.011)$ & $0.049^{* * *}(0.039,0.060)$ & $0.003^{* *}(0.001,0.005)$ & $-0.058^{* * *}(-0.064,-0.053)$ \\
\hline $\begin{array}{l}\text { Leg Extensions }{ }^{\mathrm{a}} \text { ( } \mathrm{kg} \text { per } \mathrm{kg} \text { of body } \\
\text { weight) }\end{array}$ & $-0.018^{*}(-0.033,-0.004)$ & $0.001(-0.013,0.015)$ & $0.009^{* *}(0.004,0.014)$ & $0.001(-0.021,0.024)$ & $0.001(-0.007,0.010)$ & $-0.048^{* * *}(-0.064,-0.033)$ \\
\hline Plank ${ }^{a}$ (seconds) & $-3.49^{* * *}(-5.18,-1.18)$ & $-2.04(-4.22,0.13)$ & $6.19^{* * *}(5.00,7.39)$ & $7.45(-0.10,15.01)$ & $1.76^{* *}(0.67,2.86)$ & $-12.39 * * *(-14.53,-10.26)$ \\
\hline $\begin{array}{l}\text { Pull-ups }{ }^{\text {bc }} \text { (odds ratio for completing } \geq 1 \\
\text { pull-ups) }\end{array}$ & $0.83^{* * *}(0.76,0.92)$ & $0.86^{* *}(0.78,0.94)$ & $0.99(0.94,1.05)$ & $3.41^{* * *}(2.36,4.93)$ & $1.05(0.99,1.12)$ & $0.40^{* * *}(0.31,0.51)$ \\
\hline $\begin{array}{l}\text { Pull-ups }{ }^{\mathrm{b}} \text { (\# of pull-ups for children with } \\
\geq 1 \text { pull-ups) }\end{array}$ & $-0.34(-0.84,0.15)$ & $-0.23(-0.61,0.14)$ & $0.72^{* * *}(0.53,0.90)$ & $2.63^{* * *}(1.77,3.49)$ & $0.31^{* *}(0.12,0.49)$ & $-1.18^{* * *}(-1.48,-0.88)$ \\
\hline
\end{tabular}

${ }^{a}$ Coefficients were estimated from linear regression models including all covariates in the table

${ }^{b}$ Due to the large number of children unable to complete one modified pull-up, two types of models were used to analyze the data. The first model estimated the association of the covariates with the ability of a child to complete at least one modified pull-up using a logistic regression model. The second model estimated the association of the covariates with the number of modified pull-ups completed only among children that completed at least one modified pull-up using a linear regression model. Both types of models included all covariates listed

$c$ Females were coded as the reference group (denominator) for the logistic regression model

${ }^{*} p<0.05,{ }^{* *} p<0.01,{ }^{* * * *} p<0.001$ 
One of the main limitations in the current study is that the measurement of time spent in screen-based sedentary behaviors and physical activity were self-reported, which could result in biased measurements of these activities. An assumption for these results is that potential miss-reporting is not systematically associated with strength (e.g., stronger children are not more likely to under-report sedentary time).

Some further limitations exist regarding the measure of computer time and video game use. The question used in the NHANES interview excluded school-related computer use, meaning that the reported computer/ video game time likely underestimates the total amount of time children spent in front of a computer. Further, it is also possible that estimating the time spent on these activities is less accurate than for television viewing which is conveniently packaged into half-hour segments by programs. For these reasons, we cannot conclude absolutely that computer use does not also have a negative effect on children's strength, but rather that further research is needed to investigate this with more sensitive measures. An additional limitation was that it was not possible to examine non-school computer use and time spent playing video games separately. Future studies examining whether gaming, other types of computer use (e.g., surfing the web), and other sedentary behaviors such as doing homework or reading have comparable effects on strength are needed.

Lastly, numerous covariates were included in the regression models to minimize confounding; however, it is possible that some of the results are due to unmeasured variables. We considered the possibility that socioeconomic status (SES) could explain some of the relationship between television viewing and strength, but when it was included in the regression models (using poverty income ratio, with 1.85 times the poverty level as a cutoff point between the lower and higher SES groups), SES was not a significant predictor of any of the strength measures. Another possibility that we were unable to control for was that television viewing could be a proxy for a generally unhealthy lifestyle which resulted in lower strength. It is also possible that children that watched more TV had less time to do muscle strengthening exercises. Future research is needed to understand if the act alone of watching TV decreases strength or if other mechanisms explain the inverse associations observed in this study. Finally, due to the cross-sectional nature of the study, we cannot rule out the possibility of reverse causality (e.g., children with weaker muscle strength could choose to spend more time watching television). Longitudinal studies would provide more insight into the directionality of this relationship.

The strengths of the current study include the use of objective tests of physical strength as outcome measures, as well as examining both relative and absolute strength. Further, the current analyses controlled for the reported number of days per week with at least 60 minutes of physical activity, in order to specifically investigate the role of screen-based sedentary behaviors themselves, rather than simply as a replacement for physical activity. Future studies would benefit, however, from more precise, objective measures of physical activity levels and sedentary time.

Other promising research directions could include a clinical trial to reduce time spent viewing television and encouraging children to engage in more play to explore the impact not only on BMI outcomes, as has been done traditionally, but also on children's physical functioning, including functional strength. It is important to bear in mind that children's electronic media use is evolving and more studies are needed to explore how the use of both "traditional" forms of electronic entertainment, such as television, and newer devices such as tablets and smartphones are associated with children's body composition, energy expenditure, and strength.

The American Academy of Pediatrics guidelines are moving away from their strict recommendations that children spend no more than 2 hours per day using screens, toward suggestions of how parents can monitor and guide children's screen-based activities, but they still emphasize the need to set limits on children's use of electronic media. Even excluding school-related computer use, the average child in the current study spent over 3 hours per day watching television and playing on the computer. From a public health perspective, there is certainly a need to help families reduce screen time globally, and there is a growing literature suggesting that television and other passive viewing may be the key behavior to target in interventions. Reducing television time could potentially have benefits not only on children's physical strength, but also on other health outcomes such as weight status, sleep duration and quality, cardiovascular disease, and risk of diabetes [40-42]. The current recommendations for adults to break up every hour of inactivity time with 10 minutes of standing or movement could also be applied and encouraged in children, beyond the recommended 60 minutes per day of moderate to vigorous physical activity. Studies are beginning to show that breaks in sedentary time in children are associated with better child BMI and cardiometabolic risk [43], but it remains to be seen how this might also influence children's strength, or whether this can be successfully manipulated by intervention [44].

\section{Conclusions}

Television viewing time explained a small portion of the variance in strength, beyond what can be ascribed to the child's age, sex, BMI, or physical activity. However, 
unlike fixed factors such as age or sex, television viewing is a behavior that can be modified. Previous intervention studies have been effective in reducing screen time and, in turn, improving BMI $[38,39]$, but the effect on child strength has yet to be explored. Some strategies for reducing screen-based activity are to remove televisions and other devices from the bedroom [45] and to monitor and guide children's viewing [46]. Reducing electronic media use, particularly television viewing, could impact not only child strength, but also their fitness, BMI, and other aspects of health.

\section{Abbreviations \\ BMI: Body mass index; NHANES: National health and nutrition examination survey; NNYFS: NHANES national youth fitness survey; TV: Television.}

\section{Competing interests}

All authors declare that they have no competing interests related to the outcomes of this study. The study was funded by the Nestlé Research Center, Lausanne, Switzerland. It was a collaborative effort between Nutrition Impact, LLC (VF) and the Nestlé Research Center (LE, KM, and LK).

\section{Authors' contributions}

LE conceptualized and designed the study and drafted the initial manuscript. VF and KM carried out the analyses and reviewed and revised the manuscript. LK contributed to the study design and reviewed and revised the manuscript. All authors read and approved the final manuscript.

\section{Acknowledgments}

The authors would like to thank Alison Eldridge for her input to the manuscript revisions and to acknowledge the participants in the NNYFS study. The analyses and preparation of this manuscript were funded by the Nestlé Research Center.

\section{Author details}

${ }^{1}$ Nestlé Research Center, Case Postale 44, CH-1000 Lausanne, Switzerland.

${ }^{2}$ Nutrition Impact, 9725 D Drive North, Battle Creek, MI 49014, USA.

\section{Received: 28 September 2015 Accepted: 27 January 2016}

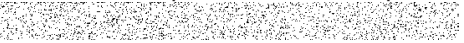

\section{References}

1. González-Gross M, Meléndez A. Sedentarism, active lifestyle and sport: impact on health and obesity prevention. Nutr Hosp. 2013;28 Suppl 5:89-98,

2. Steene-Johannessen J, Anderssen SA, Kolle E, Andersen LB. Low muscle fitness is associated with metabolic risk in youth. Med Sci Sports Exerc. 2009:41(7):1361-7. doi:10.1249/MSS.0b013e31819aaae5.

3. Smith J, Eather N, Morgan P, Plotnikoff R, Faigenbaum A, Lubans D. The health benefits of muscular fitness for children and adolescents: a systematic review and meta-analysis. Sports Med. 2014;44(9):1209-23. doi:10.1007/s40279-014-0196-4

4. Anderssen SA, Cooper AR, Riddoch C, Sardinha LB, Harro M, Brage S, et al. Low cardiorespiratory fitness is a strong predictor for clustering of cardiovascular disease risk factors in children independent of country, age and sex. Eur J Cardiovasc Prev Rehabil. 2007;14(4):526-31. doi:10.1097/HJR.0b013e328011 efc1

5. Janssen I, Leblanc AG. Systematic review of the health benefits of physical activity and fitness in school-aged children and youth. Int J Behav Nutr Phys Act. 2010;7:40. doi:10.1186/1479-5868-7-40.

6. World Health Organization (WHO). Global recommendations on physical activity for health. 2010.

7. Dowda M, Ainsworth BE, Addy CL, Saunders R, Riner W. Environmental influences, physical activity, and weight status in 8-to 16-year-olds. Arch Pediatr Adolesc Med. 2001:155(6):711-7.

8. Peart T, Velasco Mondragon HE, Rohm-Young D, Bronner Y, Hossain MB. Weight status in US youth: the role of activity, diet, and sedentary behaviors. Am J Health Behav. 2011;35(6):756-64.

9. Ervin RB, Fryar CD, Wang C-Y, Miller IM, Ogden CL. Strength and body weight in US children and adolescents. Pediatr. 2014;134(3):e782-e9.
10. Shultz SP, Anner J, Hills AP. Paediatric obesity, physical activity and the musculoskeletal system. Obes Rev. 2009;10(5):576-82. doi:10.1111/j.1467-789X.2009.00587.x.

11. Scholtes VA, Becher JG, Comuth A, Dekkers H, van Dijk L, Dallmeijer AJ. Effectiveness of functional progressive resistance exercise strength training on muscle strength and mobility in children with cerebral palsy: a randomized controlled trial. Dev Med Child Neurology. 2010;52(6):e107-13.

12. Taveras EM, Field AE, Berkey CS, Rifas-Shiman SL, Frazier AL, Colditz GA, et al. Longitudinal relationship between television viewing and leisure-time physical activity during adolescence. Pediatr. 2007;119(2):e314-e9.

13. Pearson N, Braithwaite RE, Biddle SJH, van Sluijs EMF, Atkin AJ. Associations between sedentary behaviour and physical activity in children and adolescents: a meta-analysis. Obes Rev. 2014;15(8):666-75. doi:10.1111/obr.12188.

14. Sisson SB, Shay CM, Broyles ST, Leyva M. Television-viewing time and dietary quality among US children and adults. Am J Prev Med. 2012;43(2):196-200.

15. Lissner L, Lanfer A, Gwozdz W, Olafsdottir S, Eiben G, Moreno LA, et al. Television habits in relation to overweight, diet and taste preferences in European children: the IDEFICS study. Eur J Epidemiol. 2012;27(9):705-15.

16. Johnson CL, Dohrmann SM, Kerckove V, Diallo MS, Clark J, Mohadjer LK, et al. National health and nutrition examination survey: national youth fitness survey estimation procedures, 2012. Data evaluation and methods research. 2014;2014(168):1-25.

17. National Center for Health Statistics. National Health and Nutrition Examination Survey: National Youth Fitness Survey Plan, Operations, and Analysis, 2012. http://www.cdc.gov/nchs/data/series/sr_02/sr02_163.pdf.

18. National Center for Health Statistics. National Youth Fitness Survey (NYFS) Body Measures Procedures Manual. http://www.cdc.gov/nchs/data/nnyfs/ Body_Measures.pdf.

19. National Center for Health Statistics. NNYFS Questionnaire Data. Physical Activity. http://www.cdc.gov/Nchs/Nnyfs/Y_PAQ.htm.

20. National Center for Health Statistics. National Youth Fitness Survey (NYFS) Muscle Strength (Grip) Procedures Manual. http://www.cdc.gov/nchs/data/ nnyfs/Handgrip_Muscle_Strength.pdf.

21. National Center for Health Statistics. National Youth Fitness Survey (NYFS) Lower Body Muscle Strength Component Procedures Manual. http://www. cdc.gov/nchs/data/nnyfs/Lower_Body_Muscle_Strength.pdf.

22. National Center for Health Statistics. National Youth Fitness Survey (NYFS) Plank Exercise Procedures Manual. http://www.cdc.gov/nchs/data/nnyfs/plank.pdf.

23. National Center for Health Statistics. National Youth Fitness Survey (NYFS) Modified Pull-up Exercise Procedures Manual. http://www.cdc.gov/nchs/ data/nnyfs/modified_pullup.pdf.

24. Chinapaw MJM, Proper KI, Brug J, van Mechelen W, Singh AS. Relationship between young peoples' sedentary behaviour and biomedical health indicators: a systematic review of prospective studies. Obes Rev. 2011;12(7):e621-e32. doi:10.1111/j.1467-789X.2011.00865.x.

25. Armstrong CA, Sallis JF, Alcaraz JE, Kolody B, McKenzie TL, Hovell MF. Children's television viewing, body fat, and physical fitness. Am J Health Promot. 1998;12(6):363-8. doi:10.4278/0890-1171-12.6.363.

26. Bryant ES, Duncan MJ, Birch SL. Fundamental movement skills and weight status in British primary school children. Eur J Sport Sci. 2014;14(7):730-6. doi:10.1080/17461391.2013.870232.

27. Sigmundová D, Sigmund E, Hamrik Z, Kalman M. Trends of overweight and obesity, physical activity and sedentary behaviour in Czech schoolchildren: HBSC study. Eur J Public Health. 2013;24(2):210-5. doi:10.1093/eurpub/ckt085.

28. Nelson MC, Neumark-Stzainer D, Hannan PJ, Sirard JR, Story M. Longitudinal and secular trends in physical activity and sedentary behavior during adolescence. Pediatr. 2006;1 18(6):e1627-e34. doi:10.1542/peds.2006-0926.

29. Dollman J, Norton K, Norton L. Evidence for secular trends in children's physical activity behaviour. Br J Sports Med. 2005;39(12):892-7. doi:10.1136/bjsm.2004.016675.

30. DeMattia L, Lemont L, Meurer L. Do interventions to limit sedentary behaviours change behaviour and reduce childhood obesity? A critical review of the literature. Obes Rev. 2007;8(1):69-81.

31. Schmidt ME, Haines J, O'Brien A, McDonald J, Price S, Sherry B, et al. Systematic Review of Effective Strategies for Reducing Screen Time Among Young Children. Obesity. 2012;20(7):1338-54. doi:10.1038/oby.2011.348.

32. de Jong E, Visscher TLS, HiraSing RA, Heymans MW, Seidell JC, Renders CM. Association between TV viewing, computer use and overweight, determinants and competing activities of screen time in 4- to 13-year-old children. Int J Obes. 2013;37(1):47-53. 
33. Sisson SB, Broyles ST, Baker BL, Katzmarzyk PT. Television, reading, and computer time: correlates of school-day leisure-time sedentary behavior and relationship with overweight in children in the US. J Phys Act Health. 2011:8(2):S188.

34. Carvalhal MM, Padez MC, Moreira PA, Rosado VM. Overweight and obesity related to activities in Portuguese children, 7-9 years. Eur J Public Health. 2007;17(1):42-6. doi:10.1093/eurpub/ckl093.

35. Marsh S, Ni Mhurchu C, Jiang Y, Maddison R. Comparative effects of TV watching, recreational computer use, and sedentary video game play on spontaneous energy intake in male children. A randomised crossover trial. Appetite. 2014;77(0):13-8. doi:http://dx.doi.org/10.1016/j.appet.2014.02.008.

36. Marsh S, Ni Mhurchu C, Maddison R. The non-advertising effects of screenbased sedentary activities on acute eating behaviours in children, adolescents, and young adults. A systematic review. Appetite. 2013;71:259-73.

37. Pearson N, Biddle SJ. Sedentary behavior and dietary intake in children, adolescents, and adults: a systematic review. Am J Prev Med. 2011:41(2):178-88.

38. Segal KR, Dietz WH. Physiologic responses to playing a video game. Am J Dis Child. 1991;145(9):1034-6.

39. Wang X, Perry AC. Metabolic and physiologic responses to video game play in 7-to 10-year-old boys. Arch Pediatr Adolesc Med. 2006;160(4):411-5.

40. Klesges RC, Shelton ML, Klesges LM. Effects of television on metabolic rate: potential implications for childhood obesity. Pediatr. 1993;91(2):281-6.

41. Cain N, Gradisar M. Electronic media use and sleep in school-aged children and adolescents: A review. Sleep Med. 2010;11(8):735-42.

42. Grøntved A, Hu FB. Television viewing and risk of type 2 diabetes, cardiovascular disease, and all-cause mortality: A meta-analysis. JAMA. 2011;305(23):2448-55.

43. Saunders TJ, Tremblay MS, Mathieu M-Ė, Henderson M, O'Loughlin J, Tremblay A, et al. Associations of sedentary behavior, sedentary bouts and breaks in sedentary time with cardiometabolic risk in children with a family history of obesity. PLoS One. 2013;8(11):e79143. doi:10.1371/journal.pone.0079143.

44. Verloigne M, Berntsen S, Ridgers ND, Cardon G, Chinapaw M, Altenburg T, et al. The UP4FUN intervention effect on breaking up sedentary time in 10-12 yearold Belgian children: the ENERGY-Project. Pediatric Exercise Science. 2015;27:234-42.

45. Wethington H, Pan L, Sherry B. The Association of Screen Time, Television in the Bedroom, and Obesity Among School-Aged Youth: 2007 National Survey of Children's Health. J Sch Health. 2013;83(8):573-81.

46. Gentile DA, Reimer RA, Nathanson Al, Walsh DA, Eisenmann JC. Protective effects of parental monitoring of children's media use: a prospective study. JAMA Pediatrics, 2014;168:479-84.

\section{Submit your next manuscript to BioMed Central and we will help you at every step:}

- We accept pre-submission inquiries

- Our selector tool helps you to find the most relevant journal

- We provide round the clock customer support

- Convenient online submission

- Thorough peer review

- Inclusion in PubMed and all major indexing services

- Maximum visibility for your research

Submit your manuscript at www.biomedcentral.com/submit

) Biomed Central 